\title{
Creación y extinción de los Estados de acuerdo con derecho internacional
}

\author{
Creation and extinction of states according to \\ international law
}

\author{
Gilbert Gornig* \\ Teodoro Ribera Neumann**
}

\section{Resumen}

El presente artículo examina la creación y extinción de Estados y describe las normas y principios de derecho internacional que regulan las concecuencias de estos sucesos. Especifica las distintas formas en que pueden producirse estos procesos y ofrece ejemplos históricos respecto de cada uno de ellos. Además, analiza el problema que se plantea para determinar si existe o no identidad entre un Estado nuevo y el que ha desaparecido y explica las normas y criterios aplicables para detrminar si existe o no continuidad entre ambas entidades.

Palabras Clave: Estados, creación, extinción, identidad, continuidad.

Decano de la Facultad de Derecho de la Philipps-Universität de Marburg (Alemania).

** Rector de la Universidad Autónoma de Chile.<teodoro.ribera@autonoma.cl

Este trabajo contó con la colaboración de Licenciados en Ciencias Jurídicas y Sociales de la Universidad Autónoma de Chile. Marianne Thiers García y Francisco Bedecarratz Scholz. 


\section{Abstract}

This essay analyzes the creation and disappearance of States, and describes the International Law norms and principles that regulate the consequences of such events. It details the different ways by which such processes may occur, and illustrates each of them with various historical examples. It also examines the problem of determining the identity that may or may not exist between a new State and an extinct one, and explains the norms and criteria that ascertain whether there is continuity or not between both entities.

KEYwORDS: States, creation, extinction, identity, continuity.

Recibido el 2 de agosto de 2010; aceptado el 26 de octubre de 2010. 
Teodoro Ribera y Gilbert Gornig • Creación y extinción de los Estados...

\section{INTRODUCCIÓN}

Ni la creación ni la extinción de un Estado son sucesos meramente históricos, sino que se han presentado profusamente en los últimos lustros como procesos que generan importantes consecuencias según el derecho internacional

La Unión de Repúblicas Socialistas Soviéticas, la República Democrática Alemana y Checoslovaquia, que durante decenios tuvieron un rol relevante a nivel mundial y cuyo ocaso parecía impensable, han desaparecido o se han transformado en otros Estados, con mayor o menor grado de continuidad con las nuevas entidades. También en Iberoamérica se produjeron durante los dos últimos siglos el surgimiento y desaparición de Estados, pero aquellos que han permanecido han demostrado una sorprendente fortaleza y disposición a conservar sus estructuras.

Este trabajo analiza las diversas circunstancias que pueden causar la creación y la desaparición de los Estados, brindando ejemplos históricos y presentes al respecto.

\section{LA FORMACIÓN DE ESTADOS}

\section{Generalidades}

En los comienzos del derecho internacional moderno, la comunidad parte de él estaba formada solo por los Estados cristiano-occidentales eu- ropeos. Este círculo se amplió con el reconocimiento de los Estados Unidos de América, hecho mediante el Tratado de París de 1783.

Los nuevos países iberoamericanos desmembrados de España y Portugal, fueron reconocidos como Estados independientes primeramente por Portugal en 1821, luego por los Estados Unidos de América a partir del año 1822 e Inglaterra desde el año 1825 (Fenwick, 1963: 160). Portugal, por su parte, reconoció la independencia del Imperio del Brasil en el año 1822 y España la de sus ex colonias a contar del decenio de los años $1840 .{ }^{1}$

En el año 1856, ${ }^{2}$ los Estados cristianos europeos aceptaron formalmente a Turquía como parte del concierto europeo y le extendieron las ventajas del derecho internacional (Strupp, 1911: 187). En el transcurso del siglo XIX y a comienzos del siglo XX fueron incorporados a dicha comunidad otros países no cristianos que pudieron mantener su independencia durante el proceso de imperialismo europeo, como Japón, China, Persia y Siam (hoy Tailandia).

1 En el caso de Chile, el primer país que lo reconoció formalmente fue el Reino Unido de Portugal, Brasil y Algarve, el 11 de agosto de 1821. Este reconocimiento fue seguido por el de Estados Unidos de América (1822), Francia (1830), Gran Bretaña (1831) y Santa Sede (1840). Chile no fue reconocido por España sino hasta el 25 de abril de 1844, en el tratado celebrado con esa fecha entre ambos Estados.

2 Cfr. Art. 7 del Tratado de París de fecha 30 de marzo de 1856; Texto en: GesetzSammlung für die Königlichen preußischen Staaten 1856, p. 557 y ss. 
Este proceso estaba prácticamente finalizado antes del inicio de la Primera Guerra Mundial, ya que toda la tierra habitable se encontraba de una u otra manera sometida a algún tipo de control estatal y todos los Estados independientes eran simultáneamente sujetos de derecho internacional. Solo se podían crear nuevos Estados en suelos pertenecientes a Estados ya existentes, ya sea por separación voluntaria o violenta de uno o de varios países, o por medio de la unión de Estados independientes para conformar un nuevo país.

Contrariamente a lo que sucede en el derecho público nacional, donde la iniciativa de crear un nuevo país al interior de un Estado ya existente es considerada regularmente un acto de alta traición, en el derecho internacional no existe disposición alguna que prohíba la formación de nuevos Estados. ${ }^{3}$ De este modo, se excluye concientemente del derecho internacional el problema de la legalidad o ilegalidad interna de la creación de un nuevo Estado. En efecto, al analizar la posible incorporación de un nuevo país a la comunidad internacional, a esta le es, en principio, indiferente que el Estado se haya formado por separación o por fusión de varios

3 La Corte Internacional de Justicia se ha pronunciado a favor de este principio. En este sentido, su presidente Hisashi Owada expresó con fecha 22 de julio de 2010, en la lectura de la opinión consultiva sobre la declaración de independencia de Kosovo, que «la adopción de esa declaración no violó ninguna norma aplicable de derecho internacional».
Estados, o sobre la superficie de uno o varios países ya existentes. ${ }^{4}$

Ante aspiraciones separatistas o movimientos subversivos internos, el derecho internacional no asume una posición invariable en defensa de la existencia de los actuales países o de su extensión territorial. Es más, establece que en determinadas situaciones dichos movimientos puedan ser reconocidos como beligerantes por la comunidad internacional, con el objeto de someterlos a las normas que regulan las contiendas entre Estados propiamente tales. ${ }^{5}$

Sin embargo, vid. infra notas 14 y 15 .

5 Cuando la insurrección asume el carácter de guerra civil, esto es, cuando la lucha política alcanza proporciones tales que los insurrectos, dirigidos por un gobierno responsable, ejerzan autoridad sobre un territorio definido, posean fuerzas armadas regularmente constituidas y tengan la intención y la capacidad de respetar las obligaciones de neutralidad, los gobiernos extranjeros pueden tratar en un mismo pie de igualdad a las dos partes en lucha, reconociéndoles la calidad de beligerantes. El reconocimiento del estado de beligerancia requiere que la insurrección sea de excepcional importancia y que su prolongación afecte los derechos de los neutrales. No tiene carácter definitivo ni envuelve conceder la condición de Estado a los insurrectos, sino que tiene por objeto someter a las normas del derecho internacional actos del todo semejantes a los que éste reconoce en las relaciones hostiles entre los Estados. Como ejemplo, podemos señalar los Estados surgidos tras la separación de los Estados del Sur, en la Guerra de Secesión de Estados Unidos, ya que tanto la Unión como la Confederación fueron considerados por la comunidad internacional como Estados beligerantes (Ulloa, 1957: 187; Accioly, 1945: 159). Por otra parte, durante la Guerra Civil 
Teodoro Ribera y Gilbert Gornig • Creación y extinción de los Estados...

Por otra parte, existe la posibilidad de que los Estados traten de protegerse de peligros y amenazas provenientes del interior por medio de acuerdos de derecho internacional, tal como sucedió con la Sagrada Alianza firmada en septiembre de $1815 .^{6}$

El derecho internacional incluso facilita el proceso de formación de nuevos Estados, desde el momento en que la autodeterminación de los pueblos fue elevada a la categoría de principio jurídico universal por medio de la Friendly Relations Declaration. ${ }^{7}$

chilena de 1891, la escuadra sublevada bloqueó los puertos de Valparaíso e Iquique, notificando a los representantes de naciones extranjeras de dicha acción. Los gobiernos de Inglaterra, Francia, Estados Unidos de América y Alemania protestaron contra el bloqueo, pero conjuntamente le reconocieron ciertas libertades a los insurrectos y, con ello, implícitamente la calidad de beligerantes. Ello implicó que los actos de los rebeldes no comprometieron la responsabilidad del Estado, y que los sublevados no fueron tratados como piratas en la acción de bloqueo. (Accioly, 1945: 168). La Junta de Gobierno revolucionaria obtuvo el reconocimiento expreso de la calidad de beligerantes por parte de Bolivia en el año 1891, pero Perú rechazó su solicitud en este sentido, si bien aplicó ciertas reglas relativas a la neutralidad y el asilo (Ulloa, 1957: 187).

6 Acuerdo firmado por el Emperador de Austria, el Rey de Prusia y el Zar de Rusia, por medio del cual acordaron su mutua fraternidad en pos de la restauración absolutista en Europa y así asegurar la asistencia mutua en caso de movimientos revolucionarios al interior de los países signatarios.

7 Resolución N. ${ }^{\circ} 2625$ de la Asamblea General de las Naciones Unidas, aprobada
Un Estado se forma cuando en los hechos cumple con las condiciones establecidas en la "teoría de los tres elementos»(Jellinek, 1928: 394): el territorio, la nación o población, y el gobierno. Algunos autores agregan en cuarto lugar el elemento de independencia, que se traduce en la ausencia de control o subordinación respecto a otro Estado. ${ }^{8}$ El derecho internacional convencional ha plasmado la exigencia de estos elementos, incluyendo el de capacidad de entrar en relaciones con los demás Estados (independencia), en el artículo $1^{\circ}$ de la Convención de Montevideo sobre Derechos y Deberes de los Estados de 1933, ${ }^{9}$ debiendo

en el XXV período de sesiones, del 24 de octubre de 1970 .

8 Sin embargo, actualmente existen Estados que carecen de este último requisito, pero que no por eso dejan de ser tales. Un ejemplo es el caso de Puerto Rico, que en su calidad de Estado Libre Asociado es un territorio no incorporado a Estados Unidos de América con status de autogobierno. Todo lo relacionado a la moneda, la defensa, las relaciones exteriores y la mayor parte del comercio entre Estados es regulado por el gobierno federal, conservando el gobierno de Puerto Rico su autonomía fiscal y el derecho de cobrar impuestos locales(Llanos, 2006: 57). Según la noción clásica, Puerto Rico constituye un Estado no obstante carecer en los hechos de independencia o de atribuciones substanciales en materia de relaciones exteriores.

9 Ratificada por Chile mediante el Decreto Supremo $N^{\circ} 493$, publicado en el Diario Oficial de fecha 18 de mayo de 1935. Chile, al reconocer a Lituania el 20 de agosto de 1991, expresó «la convicción del Gobierno de Chile en el sentido de que el Estado de Lituania cuenta con una so- 
considerarse a todos ellos como requisitos copulativos y equivalentes para la creación de un Estado.

Por otra parte, la legitimidad y legalidad del poder estatal no es una condición para su existencia internacional, pues su formación y existencia son independientes de ello (Teyssen, 1987: 35). En consecuencia, una organización política que se ha formado infringiendo el derecho internacional es igualmente un Estado si cumple con los respectivos requisitos fácticos enumerados supra. ${ }^{10}$

Igualmente, el hecho de que un Estado esté reconocido o no por otros países carece de importancia en la detentación o carencia de la calidad de sujeto de derecho internacional (Kelsen, 1952: 230; Teyssen, 1987: 35). Este principio se encuentra incorporado en la Convención sobre Derechos y Deberes de los Estados de 1933, la que en su artículo

ciedad humana políticamente organizada, independiente de cualquier otro Estado, $\mathrm{y}$ ocupa un determinado territorio". Chile formuló declaraciones equivalentes a propósito de Estonia y Letonia.

10 Respecto de la existencia de Estados surgidos en contravención al derecho internacional, la denominada doctrina Stimson, (Accioly, 1945: 148), que postulaba la obligatoriedad del no-reconocimiento de entidades surgidas en contravención al derecho internacional convencional, no pudo imponerse en forma absoluta. No obstante lo anterior, la República Democrática Alemana no fue reconocida por su falta de legitimidad internacional durante más de veinte años. El no reconocimiento de Transkei y otros homelands se basó igualmente en la falta de legitimidad internacional (Günther, 1980: 323) (Klein, 1979: 469) (Harding, 1976). $3^{\circ}$ señala que la existencia política del Estado es independiente de su reconocimiento por los demás.

El Estado tiene, aun antes de ser reconocido, derecho a defender su integridad e independencia, proveer a su conservación y prosperidad y, por consiguiente, legislar sobre sus intereses, administrar sus servicios, determinar la jurisdicción y competencia de sus tribunales y organizarse como mejor lo entendiere. Por ello, no debe confundirse la existencia misma de un Estado con el hecho de su reconocimiento por los Estados preexistentes. La existencia comienza junto con la constitución de una entidad política independiente $\mathrm{o}$, en otros términos, la existencia del Estado se refiere al derecho público, mientras que el reconocimiento se relaciona con el derecho internacional (Cruchaga, 1944: 326).

El reconocimiento expresa solamente la voluntad de otro país de establecer relaciones diplomáticas con el Estado y de tratarlo como un sujeto de derecho internacional (Juste, 2002: 205), pero no supone necesariamente el establecimiento inmediato de relaciones diplomáticas, pues para ello es necesario un acuerdo especial entre los Estados respectivos (Benadava, 2004: 109).

De esta manera, el reconocimiento no transforma a un no Estado en Estado y una negativa de reconocimiento no conlleva que un Estado pierda su 
TeOdoro Ribera y Gilbert Gornig • Creación y extinción de los Estados...

calidad de tal (Ulloa, 1957: 154). ${ }^{11}$ Consecuentemente, el reconocimiento es un acto declarativo y no constitutivo de derecho, ya que si le atribuyésemos erróneamente un carácter generador, ello implicaría el nacimiento de un Estado, produciéndose un vacío jurídico entre el nuevo Estado y aquellos que aún no lo reconocen. ${ }^{12}$

En razón de las consideraciones anteriores, el Estado existe desde que se establece efectivamente como tal y desde entonces está dotado de personalidad jurídica y tiene los derechos y deberes prescritos por el derecho internacional, debiendo ser tratado como ente jurídico internacional incluso sin mediar reconocimiento. Esto significa que el reconocimiento de un Estado no es un acto discrecional que pueda ser negado cuando la entidad que aspira a ser considerada como tal reúne claramente las condiciones exigidas por el derecho internacional. Negar el reconocimiento en tal circunstancia viola el derecho internacional, del mismo modo que lo hace el reconocer a una entidad que carece de alguno de los atributos esenciales del Estado. Así, el

11 La Carta de la Organización de los Estados Americanos señala en su artículo 10 que el reconocimiento significa que el Estado que lo otorga acepta la personalidad del nuevo Estado con todos los derechos y deberes que para uno u otro determina el derecho internacional

12 Cabe considerar que en este aspecto existe una larga discusión entre quienes atribuyen al reconocimiento de un Estado un carácter declarativo y los que lo califican como constitutivo de su personalidad internacional. reconocimiento de Panamá hecho por los Estados Unidos de Norteamérica en el año 1903, cuando la entonces provincia de Colombia aún no había consolidado su independencia, es un ejemplo de un reconocimiento prematuro. Los Estados Unidos aceptaron más tarde haber incurrido en responsabilidad por este hecho y pagaron a Colombia una indemnización (Jiménez, 1995: 23).

Una discusión importante surge en torno al tema de las consecuencias de la admisión de un nuevo Estado en una organización internacional. Para algunos autores, cuando un Estado nuevo es admitido en una organización internacional, ello equivale a su reconocimiento por parte de todos los Estados miembros, sin necesidad de otros reconocimientos expresos o intercambio de agentes diplomáticos (Gamboa, 2005: 117). Aquella admisión, adoptada por una mayoría calificada de votos, obligaría a todos los Estados miembros, incluyendo a los que votaron en contra; por tanto, implicaría que todos los signatarios reconocen la personalidad jurídica internacional del nuevo Estado. ${ }^{13}$ Este efecto erga omnes para el resto de los Estados miembros de una organización, que se observa específicamente en el caso de las Naciones Unidas, sería consecuencia de que al someterse un Estado a la Carta de la Organización, transfiere a la Asamblea General y al Consejo de Seguridad la competencia para reconocer como Estado a una comunidad que todavía no

13 Sin embargo, no obliga a los Estados miembros a establecer ipso facto relaciones diplomáticas con él (Podestá, 1960: 75). 
ha sido reconocida (Kelsen, 1965: 240). Otra parte de la doctrina considera, sin embargo, que la admisión de un nuevo Estado como miembro de una organización internacional solo surte efectos en el plano de las relaciones bilaterales entre la organización y el Estado reconocido, pero no implica necesariamente su reconocimiento por los demás Estados miembros (Juste, 2002: 204).

En cuanto al no reconocimiento de un Estado, este puede llevarse hasta casi sus últimas consecuencias. En la mayoría de los casos, necesidades de orden práctico y humanitario motivan ciertos contactos y formas de cooperación con un Estado no reconocido, como el mantenimiento de relaciones oficiosas y postales, la admisión de sus actos de estado civil, etc. Los contactos y relaciones de esta clase no alcanzan, en todo caso, a ser constitutivos de reconocimiento pleno (Benadava, 2004: 112).

Ahora bien, ha habido casos en que el Consejo de Seguridad de las Naciones Unidas ha exhortado a la comunidad internacional a no reconocer determinados Estados cuyas creaciones violan las resoluciones de dicho organismo, de la Asamblea General y los tratados internacionales. Tales fueron los casos de la República de Rhodesia del Sur y la República Chipriota del Norte, en que se llamó a su no reconocimiento, ${ }^{14}$

14 En el caso de Rhodesia del Sur, las razones invocadas por el Consejo de Seguridad fueron que se violó el principio de autodeterminación de los pueblos y el carácter racista del nuevo régimen instaurado, de lo cual resultó que no fue reconocido por ningún Estado. El caso fue resuelto en y la anexión de Kuwait por Irak, en torno a la cual se expresó que carecía de validez jurídica, y llamó a los Estados y organizaciones internacionales a no reconocerla. ${ }^{15}$

\section{LA FORMACIÓN DE EsTADOS COMO PROCESO HISTÓRICO}

\section{a) Producto de los hombres}

Un Estado puede nacer sin que para ello sean necesarias acciones y decisiones específicas, sino como producto de la historia, del desarrollo humano y de la vida política. Así es como antaño se han formado Estados cuando un grupo de colonos se ha unido voluntariamente para formar una comunidad estatal sobre territorio no perteneciente a Estado alguno, esto es, en los terrenos deshabitados o habitados por pueblos antes considerados como incivilizados. Tal es el caso del Estado de Liberia, que fue fundado en el año 1847 por una asociación filantrópica para dar patria a los esclavos manumitidos en

1980 al constituirse el nuevo Estado de Zimbawe en el territorio que ocupaba Rhodesia del Sur. Por su parte, la República Chipriota del Norte fue instalada, con el apoyo de Turquía, por una parte de la población chipriota de origen turco en el norte de Chipre, siendo dicho Estado el único que la reconoció. Resolución $\mathrm{N}^{\circ} 541$ (1983) de 18 de noviembre de 1983, del Consejo de Seguridad de Naciones Unidas. 15 Resolución Nº62 del Consejo de Seguridad de las Naciones Unidas, de 9 de agosto de 1990. 
TeOdoro Ribera y Gilbert Gornig • Creación y extinción de los Estados...

los Estados Unidos de Norteamérica, así como el de la Zuid-Afrikaansche Republiek, fundada en 1856 por la unión de varias comunidades de Boers en el sur de África (Ulloa, 1957: 112).

De lo anterior puede concluirse que el éxito o fracaso de una iniciativa semejante depende de la medida en que el elemento gobierno sea capaz de imponerse en el territorio ocupado.

\section{b) Producto de la decisión de Estados o de partes de Estados}

\section{i) Secesión}

Un nuevo Estado también se genera cuando, contra la voluntad de un Estado existente, parte de este se separa y se independiza. En este caso el antiguo Estado sigue existiendo, con su territorio reducido, junto al recién creado. Este método de formación se denomina secesión.

Ya en el siglo XVII, los Países Bajos y Suiza se constituyeron como Estados independientes al desprenderse de esta manera del Sacro Imperio, en virtud de la Paz de Westfalia celebrada el año 1648. En 1776, las trece colonias inglesas en América declararon su independencia del Reino Unido y la mayoría de los Estados hispanoamericanos se declararon independientes de España entre 1808 y 1824. De igual forma, Brasil se separó de Portugal en el año 1822; la provincia de Cisplatina o la Banda Oriental se proclamó

16 Como lo demostró el no reconocimiento expreso de los Estados Unidos de América, pronunciado el 27 de noviembre de 1900. 
ii) Separación

Otra forma de generar un nuevo Estado en territorios pertenecientes a uno antiguo puede darse cuando un Estado recién formado es expulsado o se separa del conglomerado al que pertenecía. Sucedió con Irlanda y diferentes colonias británicas en el siglo XX, las que fueron separadas de la suprema autoridad británica por medio de una decisión del Parlamento. ${ }^{17}$

iii) Desmembramiento o disolución

El desmembramiento o disolución consiste en que un Estado existente se disuelve y sus diferentes partes se convierten en Estados independientes.

Así aconteció en 1830 cuando la Gran Colombia se desmembró en tres Estados: Nueva Granada, Venezuela y Ecuador. Igualmente, en 1840 la República Federal de Centroamérica se desmembró en las repúblicas de Nicaragua, Honduras, Costa Rica, Guatemala y el Salvador. En 1896 volvieron a unirse, salvo las repúblicas de Guatemala y Costa Rica, en los Estados Unidos de Centroamérica, para luego disolverse en el año 1898 (Cruchaga, 1944: 324). En la década de los años noventa del siglo pasado se dieron varios casos de desmembramiento de países, entre ellos el de la Unión de Repúblicas Socialistas

Cfr. la Ireland Act del 2 de junio de 1949, la Indian Independence Act del 18 de julio de 1947 y la Ghana Independence Act del 6 de marzo de 1947.
Soviéticas, la República Federativa de Yugoslavia y Checoslovaquia. ${ }^{18}$

iv) Fusión o unificación

Es el caso en que varios Estados independientes que ya existen se unen y conforman un único Estado, con lo cual pierden su antigua autoridad nacional y su autonomía.

Tal es el caso de los Estados italianos parcialmente restaurados que, después del período de transición napoleónica, se fusionaron con territorios que se habían separado del Imperio AustroHúngaro y conformaron el nuevo Estado de Italia. Otro caso se produjo en 1871 con la unificación de los distintos Estados alemanes y Prusia, formándose el Imperio Alemán. Ejemplos más actuales son los de Tanzanía, que es el resultado de la fusión en 1964 de Tanganica y Zanzíbar, y de la República del Yemen, que nació de la unificación en 1990 de la República Árabe del Yemen con la República Popular Democrática del Yemen.

Por otra parte, Perú y Bolivia han intentado numerosas veces unificarse y crear entidades federadas nuevas a partir de sus propios Estados. Así, el 15 de noviembre de 1826 se firmó en

18 La URSS de disolvió en 15 nuevas Repúblicas, entre ellas, Rusia, Estonia, Letonia, Lituania, Ucrania, y Bielorrusia. Yugoslavia se dividió en Bosnia-Herzegovina, Serbia, Montenegro, Croacia, Macedonia y Eslovenia. La división de Checoslovaquia dio origen a la República Checa y a Eslovaquia. 
TeOdoro Ribera y Gilbert Gornig • Creación y extinción de los Estados...

Chuquisaca, Bolivia, un tratado en virtud del cual Perú y Bolivia se unían para conformar la «Federación Boliviana» bajo la jefatura vitalicia de Simón Bolívar. Sin embargo, dicho tratado jamás fue ratificado y nunca entró en vigor. Luego, el $1^{\circ}$ de mayo de 1837 se firmó el pacto de Confederación Perú-Boliviana entre los Estados Norte y Sur Peruano, con Bolivia. Las tres entidades conformaban un gobierno central confederado que en la práctica unía dichos Estados en uno solo, bajo la égida de su protector Andrés de Santa Cruz. Dicha confederación fue disuelta manu militari por la invasión chilena de 1838, restaurándose la unidad del Perú en el Congreso de Huancayo. Posteriormente, el 11 de junio de 1880 se firmó en Lima un protocolo que contenía las bases generales de la unión de Perú y Bolivia, que asumiría el título de Estados Unidos Perú-Bolivianos, pero el curso de la guerra entre los países signatarios y Chile dejó sin aplicación práctica el mentado protocolo (Ulloa, 1957: 120). De los tres ejemplos enumerados, solo uno, el de la Confederación Perú-Boliviana de 1837 , surtió verdaderos efectos tanto en el orden interno como en el internacional, pudiendo considerarse el Pacto de Tacna del $1^{\circ}$ de mayo de 1837 , para todos los efectos, como la creación de un Estado nuevo producto de una unión federal, siendo los otros dos casos meras tentativas abortadas que, sin embargo, denotan un sostenido interés en crear un Estado nuevo en dicha zona.

\section{c) Producto de un tercer Estado}

Terceras potencias pueden crear nuevos Estados, siendo un ejemplo de ello el acta del Congreso de Viena del 9 de junio 1815, que creó el Estado Libre y Neutral de Cracovia (Fleischmann, 1905: 5). Bulgaria fue creada por el art. $1^{\circ}$ del Tratado de Berlín del 13 de julio de 1878 (Fleischmann, 1905: 148) y el Estado del Vaticano se creó por el art. 2 del Tratado de Letrán del 11 de febrero de 1929 (Berber, 1967: 831).

Por otra parte, terceros Estados pueden acordar entre sí la creación de un nuevo Estado en el territorio de otro no involucrado directamente en la respectiva convención. Albania se constituyó en el año 1913 por medio de una resolución de la conferencia de embajadores de las grandes potencias, a quienes Turquía había otorgado la autorización pertinente en el artículo 3 de la Paz Preliminar de Londres (Strupp, 1916: 278). La Ciudad Libre de Danzig (Böttcher, 1999: 76) se determinó en los artículos 100 y siguientes del Tratado de Versalles, el 28 de julio de $1919 .{ }^{19} \mathrm{El}$ Territorio Libre de Trieste iba a crearse por medio del Convenio de Paz con Italia, ${ }^{20}$ pero no se materializó.

También se han creado Estados por resoluciones de la Organización de las Naciones Unidas. Así, el Estado de Libia fue establecido mediante la Resolución 289 (IV) A del 21 de noviembre

19 Texto en: Reichsgesetzblatt (RGBl.) 1919, P. 689 ss.

20 Texto en: United Nations Treaty Series (UNTS), T. 49, p. 3 ss. 
de 1949, de la Asamblea General de las Naciones Unidas, aprobada sobre la base del art. 23 del Tratado de Paz con Italia del 10 de febrero de $1947,{ }^{21}$ y la instauración del Estado independiente de Somalia se dispuso mediante la Resolución 289 (IV) B. ${ }^{22}$

Interesante es destacar que lo decisivo para la creación del Estado no es el acto jurídico propiamente tal, sino su sustrato fáctico. ${ }^{23}$ Ello, pues si como consecuencia del tratado no se produce la creación de hecho, no existe ningún Estado y, al contrario, si resulta que el acto jurídico es ilegal o nunca entró en vigencia pero la nueva entidad reúne los elementos constitutivos, el nuevo Estado existe.

Por otra parte, la fundación de numerosos Estados, especialmente en África y Asia, se ha consagrado a través de tratados entre la autoridad gubernamental de los Estados salientes con los gobiernos provisionales de los Estados

21 Loc. cit.

22 Cfr. United Nations Yearbook (UNYB) 1948-49, p. 275 y s.

23 Así, Checoslovaquia suscribió los preacuerdos los Tratados de París, a pesar de que solo un Estado independiente recién con la entrada en vigencia de los tratados de Saint Germain del 16 de julio de 1920, lo que implica que en los hechos existía con anterioridad. Igualmente Egipto exigió que Turquía renunciara a sus derechos soberanos sobre Egipto en el Tratado de Lucerna, de 24 de julio de 1923 (Martens, 1924: 342) ss.) También Corea existió antes que Japón renunciara a sus derechos soberanos sobre ella en el Tratado de San Francisco del 8 de septiembre de 1951 (texto en: Europa Archiv [EA] 1951, p. 4552 ss.). a crear. En el Tratado celebrado el 6 de diciembre de 1921 entre Gran Bretaña y la Jefatura de los Republicanos Irlandeses, se decidió la independencia de Irlanda. ${ }^{24}$ Igualmente, con anterioridad a la creación de Birmania, se firmó el Tratado del 17 de octubre de 1947 entre el gobierno británico y el gobierno provisional de Birmania. Del mismo modo, antes de la independencia de las Filipinas se celebró el Tratado de Manila del 4 de julio de 1946 entre los Estados Unidos y el futuro gobierno filipino (Briggs, 1949: 113). En el Tratado del 2 de noviembre de 1949, los Países Bajos declararon que le traspasaban la soberanía al nuevo Estado y le otorgaban reconocimiento, mientras la República de Indonesia, que aún no se había creado, declaró que aceptaba la soberanía traspasada. ${ }^{25}$ También en el caso de los Estados africanos de Dahomey (Benín), Costa de Marfil, Mauritania, el Níger y Alto Volta (Burkina Faso), se celebraron negociaciones y convenios previos que prepararon los procesos mediante los cuales llegaron a ser Estados. Si bien en los acuerdos se determinó que entrarían en vigencia

24 Texto en: <http://www.nationalarchivep. ie/topics/anglo_irish/dfaexhib2.html>, consultado el 31 de mayo de 2010. El tratado anglo-irlandés de 1921 puso fin a la guerra entre el Reino Unido e Irlanda y consagró el nacimiento del Estado de Irlanda. Con la ratificación, cinco sextas partes de la isla se constituyeron en un territorio soberano dentro del Imperio Británico, mientras que una sexta parte se mantuvo dentro del Reino Unido con el nombre de Irlanda del Norte.

25 Texto en: AdG 1948/49, p. 2119 C. 
TeOdoro Ribera y Gilbert Gornig • Creación y extinción de los Estados...

en una fecha posterior, generalmente después de la independencia, estos fueron firmados antes de existir una contraparte. De lo anterior se deduce que los Estados en formación ya tienen capacidad para firmar tratados que se refieran a su creación.

\section{ExTinción DE Estados}

\section{Reflexiones generales.}

Desaparecimiento histórico de Estados

Tal como sucede con la creación de un Estado, este deja de existir como persona jurídica y como miembro de la comunidad internacional cuando pierde alguno de sus elementos esenciales (Herrero, 1968: 234), siéndo preciso, sin embargo, que esa ausencia tenga carácter permanente (Sánchez, 1945: 29). ${ }^{26}$

En la práctica, los casos en que la pérdida de la calidad de Estado es producida por la extinción del poder gubernamental son mucho más relevantes que aquellos motivados por otras causas, debiendo la extinción ser, como ya lo indicamos, de carácter permanente y no transitorio, en todas las funciones y alcanzar hasta los niveles más elemen-

26 Un Estado puede desaparecer para siempre, pero también puede renacer después de un período variable de tiempo. Así, Austria recobró su carácter de Estado en el año 1945, después de perderlo con la anexión a Alemania en el año 1938. Polonia recuperó el suyo, después de sucumbir como Estado en el año 1795 y en el año 1814 tales. ${ }^{27}$ Por ello, considerando los tres elementos constituyentes del Estado, los cambios territoriales, demográficos, sociales, sociológicos y políticos al interior del conglomerado estatal normalmente carecen de relevancia para su existencia (Fiedler, 1978: 40).

En algunas oportunidades, la extinción ha tenido lugar por un acto voluntario del Estado, como sucede cuando un Estado federal se divide en cierto número de Estados independientes, o cuando diversos Estados independientes se unen para formar una federación. Así, la Gran Colombia se dividió entre 1829 y 1830 en Venezuela, Ecuador y Nueva Granada, y el Estado independiente de Texas se extinguió voluntariamente cuando pasó, en 1845 , a formar parte de los Estados Unidos de Norteamérica (Fenwick, 1963: 170). Igualmente en 2006, el parlamento de Montenegro proclamó la independencia del país, con lo que el Estado de Serbia y Montenegro dejó de existir, fragmentándose en dos.

Sin embargo, en otros casos, la extinción de un Estado puede deberse a la acción de terceros Estados, que

27 De esta manera, el Estado alemán no sucumbió en el año 1945, dado que a niveles estatales medios y bajos continuó ejerciéndose autoridad estatal alemana (Blumenwitz, 1989: 33; Teyssen, 1987: 80; Gornig, 2000: 25). Opinión contraria expresa Kelsen (Principios, 1965: 227), quien sostiene que el Estado alemán se extinguió al término de la Segunda Guerra Mundial por la pérdida de su gobierno nacional, el que fue abolido por la potencias triunfantes y el procesamiento de sus miembros. 
realizan acciones tendientes al efecto. A manera de ejemplo podemos citar la desaparición de los Estados bálticos acaecida en 1940, o la extinción de la Confederación Perú-Boliviana sucedida en 1839, que se produjo de facto luego de la derrota que le infligió Chile en la batalla de Yungay, y que fue ratificada de jure por la Constitución Política de la República Peruana del 10 de noviembre de 1839 , que consagró la unidad e independencia del Perú (Ulloa, 1957: 121).

\section{Continuidad Y \\ DISCONTINUIDAD DE UN ESTADO}

La existencia de continuidad entre dos Estados y con ello de identidad en cuanto sujetos de derecho internacional, o la ausencia de continuidad que implicase la extinción de un Estado y el nacimiento de otro enteramente nuevo, depende de la identidad que exista entre ambos en materia de los tres elementos: territorio, población y gobierno.

En principio, los conceptos «identidad» y «continuidad» son concebidos como equivalentes, de modo que no se necesitaría otra definición (Bernhardt, 1961: 295; Kimminich, Deutsches..., 1970: 437; Kimminich, Die Souveränität..., 1970: 37). Pero es necesario distinguir rigurosamente entre continuidad en el sentido de la existencia permanente de un Estado y la subsistencia de los derechos y obligaciones estatales, que implica el mantenimiento de las relaciones jurídicas concretas. Solamente la primera descripción puede considerarse sinónimo de identidad, de modo que únicamente la permanencia ininterrumpida del Estado permite mantener personalidad jurídica de acuerdo al derecho internacional. La segunda alternativa se refiere más bien a una secuencia o sucesión de identidades, la cual surge de la identidad del sujeto de derecho internacional o de las normas sobre la sucesión de Estados (Dörr, 1995: 134).

Resulta igualmente necesario distinguir entre la continuidad del Estado y la continuidad legal. Únicamente la continuidad del Estado puede considerarse sinónimo del concepto de identidad de Estado, mientras que la «continuidad legal» se refiere a la permanencia de determinadas situaciones jurídicas. El concepto de continuidad del Estado sirve también para describir etapas transitorias del mismo y cumple una función complementaria al concepto estático de identidad (Teyssen, 1987: 106) (Fiedler, Staatskontinuität..., 1970: 91). Ello, por cuanto la identidad tiene carácter estático, mientras que la continuidad es más bien dinámica (Marek, 1954: 5).

La continuidad o identidad de un Estado es más difícil de determinar cuando estamos frente a una sucesión de Estados, que se define como la sustitución de un Estado por otro en la responsabilidad de las relaciones internacionales. $^{28}$

28 Artículo 2.1. de la Convención de Viena sobre la Sucesión de Estados en Materia de Bienes, Archivos y Deudas del Estado, de 1983. 
TeOdoro Ribera y Gilbert Gornig • Creación y extinción de los Estados...

Cuando el territorio de un Estado atraviesa procesos de secesión, desmembramiento o anexión, surge el problema de hasta qué punto, de acuerdo con el derecho internacional general, las obligaciones y derechos del predecesor recaen en el sucesor (Kelsen, Principios...,1965: 254).

En casos ideales, los propios Estados sucesores determinan en qué medida les corresponden las responsabilidades del antiguo Estado. Un ejemplo de ello ocurrió en 1838, cuando luego de que la Gran Colombia se fraccionara en las repúblicas de Nueva Granada, Venezuela y Ecuador, estas dividieron de común acuerdo la deuda pública del antiguo Estado, pactando un 50\% para la primera, $28,5 \%$ para la segunda, y 21,5\% para la tercera (Accioly, 1945: 200). Otro ejemplo puede encontrarse en el Tratado de Paz y Amistad de 1844 entre la República de Chile y Su Majestad la Reina de España, donde junto con reconocerse la independencia de Chile ${ }^{29}$ se estipuló expresamente en el artículo $4^{\circ}$ que se considera parte integrante de dicho tratado el reconocimiento de Chile de, entre otras, las deudas contraídas por el gobierno y las autoridades españolas en Chile. Por otra parte, en el artículo II del Tratado de Paz y Amistad entre Chile y Bolivia de 1904, Chile asumió ciertas obligaciones que pesaban sobre el litoral boliviano que adquiría, limitando su responsabilidad solo a ellas. No obstante los

29 Artículo $1^{\circ}$ : «Su Majestad Católica[...] reconoce como Nación libre, soberana e independiente a la República de Chile». Texto disponible en www.bcn.cl. ejemplos anteriores, en los demás casos para determinar cuotas de responsabilidad se debe recurrir a normas relativas a la continuidad de los Estados.

En la comunidad internacional se han presentado diversos casos en los cuales se ha suscitado el problema de la continuidad de Estados. Así, la disolución de Checoslovaquia es un caso en que los dos Estados que nacieron a partir del territorio de la antigua entidad (la República Checa y Eslovaquia) no ejercieron pretensiones de continuidad respecto de esta (Ortega, 1999: 284). ${ }^{30} \mathrm{El}$ desmembramiento de la URSS y su continuidad en la Federación Rusa, es un caso de continuidad en la identidad. ${ }^{31}$ Por otra parte, un caso en que un Estado recurrió a la continuidad de su antecesor y no fue aceptada es el de la República Federativa de Yugoslavia (Serbia y Montenegro),

30 En este caso, aparentemente no hay un vínculo de continuidad respecto de la personalidad jurídica internacional del Estado predecesor con ninguno de los dos Estados resultantes de esa disolución. Respecto al concierto internacional, la postura de terceros Estados se ha manifestado por el reconocimiento de estos Estados como si se tratara de entidades completamente nuevas. La República Checa y Eslovaquia solicitaron su admisión como nuevos miembros de las Naciones Unidas, condición que les fue reconocida a ambas

31 La Federación Rusa informó al Secretario General de las Naciones Unidas que ocuparía el lugar de la URSS como miembro de las Naciones Unidas, incluido en el Consejo de Seguridad, y solicitó utilizar el nombre de Federación Rusa en lugar del nombre Unión de Repúblicas Socialistas Soviéticas (URSS). (Fernández, 1997: 51; Ortega, 1999: 303; Marín, 2002:134). 
que pretendía continuar ejerciendo la personalidad jurídica internacional de la República Federativa Socialista de Yugoslavia (Marín, 2002: 144). ${ }^{32}$ Un caso de continuidad es la reunificación alemana, producida en virtud de la reabsorción de un territorio separado que había llegado a constituir un Estado independiente (Fernández, 1997: 57).33

Una situación particular fue la ocurrida con los Estados bálticos de Estonia, Letonia y Lituania, que fueron considerados continuadores de los Estados homónimos existentes antes de su anexión por la Unión Soviética, en 1940. La Comunidad Europea reconoce la restauración de la soberanía y de la independencia que los Estados bálticos habían perdido en 1940 (Ortega, 1999: 308).

\section{Principio de la mayor continuidad posible}

La doctrina iuspublicista propende la continuidad del Estado por medio de

32 La Corte Internacional de Justicia consideró que la República Federativa de Yugoslavia (Serbia y Montenegro) no podía continuar automáticamente en las Naciones Unidas como miembro de la antigua República Federativa Socialista de Yugoslavia; y por lo tanto, decidió que esta debía solicitar su propia admisión como miembro. Auto de 8 de abril de 1993 de la cit. (Fernández, 1997: 55; Álvarez, 2007: 323).

33 Cabe señalar que la República Federal de Alemania informó al Secretario General de las Naciones Unidas que a partir de la fecha de la unificación actuaría en la $\mathrm{Na}$ ciones Unidas bajo la denominación de «Alemania» la personificación del mismo como persona jurídica. Sobre esta construcción jurídica descansa la tesis del derecho internacional, según la cual los cambios al interior de un Estado no influyen en la validez de las relaciones internacionales (Verdross, 1976: 232). Como la extinción de un Estado es un proceso que afecta significativamente a la comunidad de Estados y dado que el orden jurídico internacional requiere seguridad, se busca la continuidad de un Estado siempre que ello sea posible. ${ }^{34}$

Se puede establecer como principio, que un sujeto de derecho internacional se mantiene como tal mientras tenga derechos y obligaciones internacionales, ya sea en forma ilimitada o limitada. Esto es así aun cuando el ejercicio de estos derechos y obligaciones sea transitorio o permanente, parcial o total, no sea hecho por los organismos del mismo sujeto de derecho internacional sino por otros sujetos internacionales que podrían actuar en forma individual o colectiva. Es incluso posible que los derechos y obligaciones en cuestión sean asumidos por organismos pertenecientes a la comunidad internacional. ${ }^{35}$

34 Por ello, no es necesario que Estados cuya existencia esté en peligro deban permanentemente reafirmar su continuidad (Teyssen, 1987: 88). Más bien debe el Estado realizar una acción cuando desee negar dicha continuidad o apartarse de ella.

35 Por ejemplo, los territorios fiduciarios de las Naciones Unidas, reconocidos como sujetos de derecho internacional de categoría especial, son sujetos de derecho internacional cuyos derechos y deberes son asumidos por otros sujetos de derecho internacional. 
TeOdoro Ribera y Gilbert Gornig • Creación y extinción de los Estados...

Si un Estado es eliminado infringiéndose el derecho internacional (por ejemplo, por anexión forzosa), es posible que más adelante el Estado reinstaurado, que de hecho es un Estado nuevo, por vía de la ficción jurídica pueda ser identificado retrospectivamente con el Estado anterior y ser considerado como si hubiese existido sin solución de continuidad (Meter, 1986: 48; Dörr, 1995: 164). ${ }^{36}$ En la práctica internacional, los Estados de Abisinia, Austria, Polonia y Checoslovaquia fueron considerados como si no hubiesen desaparecido al ser anexados el primero por Italia y los otros por el Imperio alemán. Durante ese período, su extinción se consideró más bien como una "muerte ficticia» (Verdross/Simma, 1984: 231, Kunz, 1955: 68$).{ }^{37}$

En este contexto, una tesis relevante es aquella que postula que es posible mantener la identidad sin continuidad (Crawford, 1979: 408; Mullerson, 1993: 473). Un indicio relevante para reconocer a un Estado re-establecido es la manifestación inequívoca de su voluntad de reanudar las situaciones legales anteriores a su desaparecimiento (Dörr, 1995: 164). De esta forma los acuerdos de derecho internacional reviven o se ratifican retrospectivamente, mientras que al mismo tiempo se rechaza estrictamente la sucesión en cuanto a los compromisos de aquel

36 Según la idea de identidad y continuidad postulada por Marek, la extinción de un Estado no excluye la posibilidad de continuidad futura en otro (Marek, 1954: 9).

37 Otros ejemplos son Albania y Siria.
Estado que ha ejercido el poder gubernamental hasta ese instante. Si la tesis de «identidad sin continuidad» es rechazada, también es factible aprobar la continuidad de Estados sobre la base de otros argumentos, remitiéndose, por ejemplo, al principio ex in iniuria ius non oritur $^{38}$ y fundamentar la continuidad argumentando que la autoridad pública original ha sido eliminada por el acto ilegal del Estado que lo anexó (Marek, 1954: 412) y como tal, dicha eliminación ha sido nula.

\section{Extinción de Estados}

a. Criterios objetivos

i) Territorio

i.i) Cambios del territorio que conducen a la extinción

Los casos en que se aprecia más claramente la extinción de Estados son aquellos en que se producen modificaciones territoriales, tales como una fusión, desmembramiento o incorporación.

En el caso de una fusión, los Estados que se unen desaparecen, al igual que el Estado desmembrado deja de existir. Ello pues ni el Estado constituido después de una fusión ni los Estados formados después de un desmembramiento son idénticos a los Estados antecesores o al Estado de origen.

38 El derecho no nace de la injusticia. 
Cuando se trata de la incorporación de un Estado a otro, desaparece el Estado incorporado, mientras que el Estado receptor permanece, como el caso de la República de Texas (18361845 ) que se anexó voluntariamente a los Estados Unidos de América después de haber sido reconocida como Estado por Francia, el Reino Unido, los Países Bajos, la República de Yucatán y los mismos Estados Unidos de América (Fenwick, 1963: 170).

Los Estados que se fusionan para formar un Estado federal o que se incorporan a uno ya existente pueden permanecer con soberanía limitada e incluso seguir actuando como sujetos de derecho internacional en algunas materias, si la Constitución de todo el Estado federal lo permite.

De acuerdo con el derecho internacional clásico, era posible que un Estado sucumbiera debido a su incorporación a otro mediante una anexión violenta. En este caso, se trataba de una declaración unilateral de un Estado que consideraba como propio el territorio de otro, con lo cual el poder de aquel pasaba por encima de la voluntad del Estado anexado.

Esta forma de suprimir violentamente el poder de un Estado es hoy incompatible con la Carta de las Naciones Unidas, que establece la prohibición de aplicar la violencia y por lo tanto, todo acto hecho bajo las anteriores premisas es considerado ilegal e ineficaz. ${ }^{39}$

39 Por ejemplo, el caso de la anexión de Kuwait perpetrado por Irak en 1990, que fue condenada por la Resolución $660 \mathrm{del}$
Una resistencia permanente basada en la voluntad opositora de la población, como también el rechazo de la comunidad de derecho internacional, puede impedir que el nuevo ordenamiento ilegal llegue a ser definitivo. Sin embargo, el derecho internacional tampoco puede negar una realidad que, aunque injusta, asume carácter de permanente. Ello, pues de no reconocerse situaciones y cambios reales, se podría desembocar en un caos. Resulta entonces necesario encontrar el equilibrio entre el principio de efectividad, o sea, la norma ex factis ius oritur y el principio de juridicidad o ex iniuria ius non oritur, ya que ninguna de las dos normas de derecho internacional puede ser entendida como lex specialis en relación con la otra.

Las pérdidas territoriales experimentadas por Alemania y Rusia durante el período comprendido entre 1918 y 1922 no afectaron su personalidad legal. La tesis que postulaba que las cuantiosas pérdidas territoriales y el desmembramiento en diversos Estados que afectó al antiguo Imperio AustroHúngaro, habrían interrumpido la continuidad entre este Estado y la posterior República de Austria, no fue recogida

Consejo de Seguridad de las Naciones Unidas. Esta materia tuvo un cierto rol en la discusión sobre el alcance del Tratado Dos más Cuatro en relación con los territorios alemanes orientales incorporados a la URSS y Polonia en contravención al derecho internacional. (Gornig, Der Zweiplus-vier-Vertrag..., 1991: 97; Gornig, Die vertragliche..., 1991: 3). 
Teodoro Ribera y Gilbert Gornig • Creación y extinción de los Estados...

por el tratado de Saint Germain, de 1919 (Kelsen, Principios..., 1965: 226).

i.ii) Modificaciones del territorio nacional no conducentes a extinción

Se ha estimado que si las modificaciones territoriales no abarcan la totalidad del territorio nacional, no afectan la permanencia ni la identidad de un Estado (Delbrück, 1989: 137). Este axioma concuerda con el principio de flexibilidad fronteriza, según el cual en caso de una variación territorial solamente se modifica el segmento de aplicación de los derechos y deberes públicos, pero la existencia del Estado como tal se mantiene intacta (Marek, 1954: 15). Tal fue el caso de Alsacia y Lorena, que al pasar a soberanía francesa, el Estado alemán no perdió su calidad jurídica internacional. Lo mismo ocurrió con los territorios de Antofagasta, perteneciente a Bolivia, y Tarapacá y Arica, pertenecientes a Perú, anexados a Chile tras la Guerra del Pacífico. Tanto Bolivia como Perú mantuvieron su condición de Estados a pesar de haber sufrido una disminución de su territorio.

Sin embargo, para poder aplicar esta norma es indispensable que subsista un territorio, o sea, un espacio en el que tenga validez el ordenamiento jurídico estatal. Ello, pues una parte de la doctrina asegura que la identidad de un Estado perdura únicamente mientras su territorio no sufra una pérdida total o de extrema magnitud (Marek, 1954: 23), (Crawford, 1979: 404), (Kunz, 1955: 68).

ii) La población

ii.i) Cambios de la población que conducen a la extinción del Estado

Una nación puede sucumbir por la eliminación o la desaparición de la población de un país. Sin embargo, la ocurrencia de esta forma de extinción se encuentra circunscrita al ámbito histórico, en el cual se cuentan los ejemplos del pueblo judío, en que un Estado desapareció por la expulsión de su población (Herrero, 1968: 234), o la desaparición de Cartago y de innumerables polis del mundo antiguo cuyas poblaciones fueron absorbidas por sus conquistadores.

\section{ii.ii) Modificaciones de la nación que no conducen a la extinción}

Naturalmente, los cambios poblacionales por muerte y nacimiento o por migración no tienen influencia alguna en la identidad y la extinción de un Estado. Se trata de procesos naturales que no tienen impacto mientras la nación exista como tal. 
iii) Autoridad nacional

\section{iii.i) Cambios de la autoridad nacional conducentes a la extinción del Estado}

El desaparecimiento real y definitivo de la autoridad nacional hasta el nivel más básico de las funciones públicas, supone la extinción de un Estado (Blumenwitz, 1989: 77; Wilke, 1976: 26; Teyssen, 1987: 80). Esta forma de extinción de un Estado causada por la pérdida de la autoridad nacional solo se produce cuando luego de un análisis ex post no es factible reinstaurar de una autoridad nacional (Dahm, 1958: 91; Verdross, 1964: 250; Marek, 1954: 8; Kelsen, Principles..., 1952: 262; Kelsen, The International...,1944: 689). ${ }^{40}$ Se requiere además que la comunidad de Estados acepte la desaparición, como ocurrió en el caso de la extinción del Sacro Imperio en $1806 .{ }^{41}$

\section{iii.ii) Cambios en la autoridad nacional que no conducen a la extinción del Estado}

La constitución de un nuevo poder político en un Estado no desemboca

40 Al hacer un análisis en este sentido, se puede concluir que la Checoslovaquia de 1945 fue considerada idéntica a la Checoslovaquia del año 1938.

41 Un Estado debe considerarse extinguido cuando no puede esperarse un renacer de sus poderes públicos. Esta norma sin embargo, no es invariable, como lo demuestra el análisis de la larga anexión de los Estados bálticos perpetrada por la Unión Soviética y su posterior renacimiento en la década de los años noventa. necesariamente en la formación de un Estado nuevo, pues ello no tiene influencia en la identidad ni en la continuidad de los Estados. Esta afirmación se basa en la consideración jurídica que estima que un Estado no es idéntico a su Constitución, a su forma de Estado o de gobierno, y que los cambios en la estructura estatal no involucran al derecho internacional por tratarse de procesos internos.

En principio, ni un cambio revolucionario del poder nacional, ni tampoco un golpe de Estado significan la extinción del mismo (Fiedler, Staatskontinuität..., 1970: 39; Kimminich, Deutschland..., 1970: 438; Gornig, The European..., 1992: 5), de lo cual se deduce que, con mayor razón aún, modificar la Constitución no conduce a la extinción del respectivo Estado (Fiedler, Staatskontinuität..., 1970, 40; Anzilotti, 1929: 132). La carencia pasajera de una autoridad nacional como consecuencia de desórdenes revolucionarios no conduce ipso iure a la extinción del Estado mientras exista el deseo de instalar un nuevo poder supremo. ${ }^{42} \mathrm{La}$ eliminación transitoria del poder político por ocupación de un tercero también carece de importancia para la existencia del Estado (Dahm, 1958: 88; Fiedler, Staatskontinuität..., 1970: 150; Teyssen, 1987: 74).

42 Una guerra civil larga y permanente en que las partes pelean por el control del poder estatal no conduce tampoco a la desaparición del Estado. Una opinión contraria sostiene Geistlinger (Geistlinger, 1991: 126), que plantea la tesis de que El Líbano habría sucumbido. 
TeOdoro Ribera y Gilbert Gornig • Creación y extinción de los Estados...

Si luego de un cambio de régimen producto de una revolución el nuevo gobierno no estuviese dispuesto a asumir la continuidad con el antiguo sujeto de derecho internacional y si además lo informara a terceros Estados, cabría clasificar este evento como una extinción de Estados por decisión interna. De ser ello posible, significaría que un régimen podría por su propia voluntad provocar la extinción de su Estado y por ese medio eludir eventualmente compromisos de derecho internacional adquiridos por la antigua entidad. Por ejemplo, la aseveración de Austria en los años 1918/1919 de que era un «Estado nuevo» no produjo cambios en la continuidad de derecho internacional del Imperio, tal como se manifestó en el Tratado de Saint Germain (Silagi, 1996: 30).

Lo anterior implica que la mera afirmación de que un Estado deja de existir no puede ser suficiente; más bien son la extinción del Estado y la creación de uno nuevo, con la correspondiente pérdida de identidad entre el antiguo y nuevo, las que tienen que imponerse en la práctica del derecho internacional. Todo ello tiene por objeto evitar el fraude de obligaciones contractuales y consuetudinarias en el campo internacional.

En caso de duda, resulta necesario concluir a favor de la permanencia de la identidad, porque la atribución de una nueva acarrea una serie de consecuencias. Por ejemplo, se podría producir una sucesión de Estados, que tendría efecto en la validez futura de convenios de derecho internacional en las arcas fiscales y sobre todo en las deudas de ese Estado. Pero si el nuevo gobierno, que declara la extinción del Estado a causa de la pérdida de la antigua autoridad suprema, se declarase dispuesto a hacerse cargo de los compromisos adquiridos por el Estado anterior, la pérdida de identidad podría ser aceptable para terceros Estados, puesto que no habría lesión a sus intereses.

Finalmente, también es válido considerar que las invasiones militares y las medidas tomadas durante el período de ocupación por la autoridad extranjera, no afectan la existencia misma del Estado, ya que solamente tienen carácter temporal. Por lo tanto, debe presumirse la continuidad en la calidad de sujeto de derecho internacional del país ocupado, considerándose que solo su autoridad gubernamental se encuentra subordinada a las fuerzas de ocupación.

\section{b. Criterios a favor y en contra de la extinción de Estados en casos dudosos}

\section{i) Generalidades}

Existen factores subjetivos y objetivos que determinan los casos en los cuales un Estado ha desaparecido o sigue manteniéndose como tal, debiendo ser estimados todos ellos en su conjunto. Sin embargo, los factores subjetivos deben ser apreciados como complementarios a los factores objetivos, los 
que se consideran en primer lugar. ${ }^{43}$ Los elementos meramente legales no son los únicos que tienen relevancia, pues se requiere más bien de una visión amplia que también abarque factores políticos, históricos y geográficos.

Si pese a profundas ponderaciones estos factores resultan más bien contradictorios y si aún existen dudas respecto a la permanencia de un Estado o de su extinción, es necesario recurrir finalmente al principio de continuidad. Esto significa que, por ejemplo, en un posible caso de disputa entre secesión y desmembramiento, deberá preferirse la subsistencia del sujeto de derecho internacional.

\section{ii) Criterios objetivos}

Tanto el tamaño como la posición de un Estado desmembrado son considerados como criterios indicativos para determinar la identidad de dicho Estado con la antigua entidad (Ebenroth, 1996: 241; Dörr, 1995: 140). Junto con ellos, la cantidad de habitantes, el potencial económico y el militar también influyen en la capacidad de un Estado de asumir en el futuro los derechos y las obligaciones de derecho internacional de su antecesor.

Otro punto de consideración, pero de inferior relevancia, es la continuidad en el uso de los símbolos nacionales,

43 Esto porque de acuerdo con algunas opiniones no se le puede asignar importancia relevante a los factores subjetivos (Schweisfurth, 1996: 165). la validez de la misma capital y el uso del nombre del antiguo Estado. Dado que dichos elementos pueden ser consecuencia de consideraciones históricas y no necesariamente legales, ellos solo pueden ser indicios leves para determinar la identidad y la continuidad. (Zimmermann, 2000: 71). ${ }^{44}$

Cuando un Estado organizado en forma federal se desarticula en sus unidades territoriales, este hecho imposibilita objetivamente la aceptación de cualquiera de los Estados miembros como sucesor del Estado federal completo (Dörr, 1995: 142). Esto adquiere aún mayor validez en lo casos en que el territorio del Estado sucesor pertenecía y dependía del Estado federal antes de su independencia de este. Ello pues si el Estado que se está separando ha sido desde sus inicios un Estado dependiente no será posible aceptar una continuidad e identidad con el Estado al cual estaba antes subordinado (Marek, 1954: 186).

El desarrollo concreto del proceso de secesión es también importante, ya que entrega indicadores sobre la postura jurídica que asume el sector territorial que se está separando, respecto del Estado anterior.

\section{iii) Criterios subjetivos}

La extinción definitiva de un Estado también depende de su propia actitud, que es consecuencia de la libre autonomía de un Estado respecto de su estatus

44 Marek no otorga importancia alguna a estas circunstancias (Marek, 1954: 127). 
TeOdoro Ribera y Gilbert Gornig • Creación y extinción de los Estados...

internacional, a la vez que es expresión de su soberanía y de la libertad de acción que le otorga el derecho internacional. En razón de lo anterior, pese a modificaciones internas y externas, es factible aceptar la continuidad del Estado cuando la voluntad de este es mantener dicha característica.

La voluntad del Estado en relación con la identidad y la sucesión puede expresarse en documentos internacionales, en declaraciones unilaterales ante la comunidad de Estados, en la Constitución y también en la aceptación tácita de una declaración implícita o explícita efectuada por un tercer Estado. Pero la voluntad del Estado no puede tener un efecto absoluto, pues podría ser formulada en perjuicio a terceros.

Otro criterio por considerar en la determinación de la identidad y la continuidad es la conservación de la responsabilidad internacional del Estado antecesor. Un Estado idéntico al anterior continuará formando parte de las relaciones internacionales de su antecesor y en atención a su propia naturaleza se sentirá comprometido con sus propios derechos y deberes (Marek, 1954: 189). De igual manera, la continuidad o eliminación de las relaciones internacionales constituyen indicios de la voluntad del respectivo Estado de continuar con su antigua identidad o justificar una nueva. ${ }^{45} \mathrm{El}$

45 Ello sucede especialmente, cuando todos los Estados desmembrados de uno antiguo se distancian de las relaciones internacionales con este último, manifestando discontinuidad. Un comportamiento inverso mantenimiento del orden constitucional y judicial del antiguo Estado también puede interpretarse como indicador de identidad subjetiva de acuerdo con el derecho internacional. ${ }^{46}$

La voluntad del Estado afectado no es el único criterio determinante, puesto que la afirmación de identidad y continuidad depende también de la actitud y aceptación de la comunidad de Estados (Fastenrath, 1996: 20). Debido a las extensas consecuencias internacionales que tienen los convenios entre los Estados afectados, no es decisiva la voluntad de los Estados que participan directamente pero sí lo es el reconocimiento general de la respectiva situación deseada, siendo la comunidad de Estados la que debe expresar en forma inequívoca su voluntad al respecto. Del reconocimiento de casi toda la comunidad de Estados surge la presunción casi irrefutable de que un Estado determinado es sucesor de otro.

La voluntad de terceros Estados puede ejercerse por medio de un reconocimiento internacional, o por lo que se denomina reconocimiento del derecho a identidad. Por medio de un reconocimiento del derecho a identidad, puede aceptarse la afirmación legal de

aboga por la continuidad con el Estado anterior.

46 Sin embargo, es necesario señalar que también un Estado con identidad subjetiva puede proceder a una modificación sustancial del orden jurídico, puesto que los Estados sucesores, por razones prácticas, generalmente consideran necesario mantener por un período transitorio la legislación original anterior. 
un Estado que asegure que su subjetividad es idéntica a la del otro Estado. Un reconocimiento de este tipo puede efectuarse en forma expresa o tácita, pero en ningún caso tendrá un efecto erga omnes. Solo compromete al Estado que se está reconociendo respecto del Estado reconocido (Zimmermann, 2000: 77).

Si un Estado ejerce los derechos del Estado anterior de participar como miembro de un organismo internacional haciendo efectivo su derecho a la identidad, ya no se trata solamente de un proceso de reconocimiento por parte de la organización internacional y se requiere que la entidad sea reconocida por los Estados que componen la respectiva comunidad internacional.

\section{Epílogo}

Al desaparecer un Estado, las consecuencias legales de la sucesión de Estados son difíciles de determinar, debido a que pueden ser desencadenadas por sucesos muy diferentes y en circunstancias muy disímiles. En razón de ello, solamente se han ido desarrollando algunas normas de validez general sobre la materia, prefiriéndose un examen caso a caso. En cuanto a la sucesión en relación con los tratados de derecho internacional, al patrimonio y a las deudas (Gornig, Territoriale..., 2000: $21 ; 80 ; 88 ; 101 ; 156)$, existe gran cantidad de antecedentes en la práctica del derecho internacional, pero la diversidad de criterios deja sin respuesta un amplio rango de interrogantes. Subsiste una serie de problemas que no pueden ser resueltos ni por el derecho internacional consuetudinario ni tampoco por el derecho internacional convencional, debido a que la extinción, creación y permanencia de un Estado son procesos únicos y diferentes en cada caso concreto. Las regulaciones derivadas de tratados internacionales, tales como las Convención de Viena sobre la Sucesión de Estados en Materia de Tratados, de 1978, y la Convención de Viena sobre Sucesión de Estados en Materia de Bienes, Archivos y Deudas de Estado, de 1983, no tienen relevancia general, ya que solamente fueron ratificadas por unos pocos países.

En todo caso, el sucesor no asume la posición legal de su antecesor. Es más bien el poder soberano del antecesor el que se extingue y ese vacío es llenado posteriormente por la autoridad del sucesor (Menzel, 1962: 306). Esta es la razón por la cual el Estado sucesor tampoco adquiere capacidad adicional de derecho internacional. Pero la toma de posesión del poder soberano está ligada a la incorporación de determinados derechos y obligaciones del Estado anterior.

Considerando las implicancias para la seguridad jurídica internacional que tiene la permanencia de un Estado, se plantea la propuesta en favor de la continuidad y la identidad del sujeto de derecho internacional, por encima de la creación de entidades desvinculadas de sus Estados antecesores. 
Teodoro Ribera y Gilbert Gornig • Creación y extinción de los Estados...

\section{BIBLIOGRAFÍA}

Accioly, Hildebrando (1945), Tratado de Derecho internacional Público, Río de Janeiro, Imprenta Nacional, T. 1, p. 159.

Álvarez, Juan (2007), «Sobre el Derecho a la Secesión en la Independencia de Montenegro», en: Revista de Derecho Público, Santiago, Edición del Departamento de Derecho Público, Facultad de Derecho, Universidad de Chile., $N^{\circ}$ 69, Tomo II, p. 323.

AnZilotTi, Dionisio (1929), Lebrbuch des Völkerrechts, T. 1, p. 132.

Benadava, Santiago (2004), Derecho internacional Público, Santiago, Editorial Lexis Nexis, pp. 109, 110, 112.

Berber, Friedrich (1967), Dokumentensammlung, Munich, T. 1, P. 831 y ss.

Bernhardt, Rudolf (1961), «Kontinuität», en: Strupp, Karl/Schlochauer, HansJürgen, Wörterbuch des Völkerrechts, T. 2, pp 295 y ss

Blumenwitz, Dieter (1989), Was ist Deutschland?, p. 24, 33, 77.

Böttcher, Hans (1999), Die Freie Stadt Danzig, $3^{\circ}$ Edición, p. 76 y ss.

Briggs, Herbert (1949), "Recognition of States», en: $(A J I L)$, T. 43, p. 113, 115 y ss.

Correa, Loreto; Garay, Cristián; VACA-DiEz, Anahí y Soliz, Ana (2007), "Bolivia en dos frentes: las negociaciones de los tratados de acre y de límites con Chile», en: Universum, Talca, vol.22, n.1, pp. 268289, disponible en: <http://www.scielo.cl/ scielo.php?script=sci_arttext $\&$ pid $=$ S0718 23762007000100017\&lng=es\&nrm=i so> , consultado el 11 de junio de 2010.

Crawford, James (1979), The Creation of States in International Law, p. 404, 408.

Cruchaga, Miguel (1944), Derecho internacional, Santiago, Editorial Nacimiento, T. I, p. 326.

DАнм, Georg (1958), Völkerrecht, T.1,p. 88,91.

Del Pozo, José (2002), Historia de América Latina y el Caribe 1825-2001, Santiago, Ediciones LOM, p. 16.

Delbrück, Jost (1989), en: «Dahm, Georg/ Delbrück, Jost/Wolfrum, Rüdiger, Völk- errecht», T. I/1, Die Grundlagen. Die Völkerrechtssubjekte, p. 137

DöRr, Oliver (1995), Die Inkorporation als Tatbestand der Staatensukzession, p. 134, 140, 142, 164.

Ebenroth, Carsten (1996), "Staatensukzession und Internationales Privatrecht», en: $B D G V R$, T. 35 , p. 241 y ss.

FASTENRATH, Ulrich (1996), «Das Recht der Staatensukzession", en: BDGVR, T. 35, p. 20 y ss.

Fenwick, Charles (1963), Derecho internacional, Buenos Aires, Editorial Bibliográfica Argentina P.R.L., pp.170, 173 y 174.

Fernández Antonio (1997), Derecho internacional Público Casos y Materiales, Editorial Tirant Lo Blanch, p. 51, 55, 57, 58.

FIEDLER, Wilfried (1970), Staatskontinuität und Verfassungsrechtsprechung, pp. 39, 40, 91, 103, 150.

FIEDler, Wilfried (1978), Das Kontinuitätsproblem im Völkerrecht, p. 40 y ss.

Fleischmann, Max (1905), Völkerrechtsquellen, Berlin, pp. 5 y ss., 148.

Gamвод, Fernando (2005), Tratado de Derecho internacional Público y Derecho de Integración, Santiago, Editorial Lexis Nexis, pp. 117 y 118.

Garay, Cristián (2008), "El Acre y los 'Asuntos del Pacífico': Bolivia, Brasil, Chile y Estados Unidos, 1898-1909», en: Historia, Santiago, vol.41, n.2, pp. 341369, disponible en: <http://www.scielo.cl/ scielo.php?script=sci_arttext\&pid=S0717$71942008000200002 \& \operatorname{lng}=e s \& \mathrm{nrm}=\mathrm{i}$ so> , consultado el 11 de junio de 2010.

Geistlinger, Michael (1991), Revolution und Völkerrecht, p. 126 y ss.

Gornig, Gilbert (2000), Territoriale Entwicklung und Untergang Preußens, pp. 21 y ss., 25, 80 y ss.; 88 y ss.; 101 y ss.; 156 y ss.

GornIG, Gilbert (1991), «Der Zwei-plus-vierVertrag unter besonderer Berücksichtigung grenzbezogener Regelungen», en: Recht in Ost und West (ROW), Cuaderno 4, p. 97 ss.

GornIG, Gilbert (1991), «Die vertragliche Regelung der mit der deutschen Vereinigung verbundenen auswärtigen Probleme», en: Außenpolitik. Zeitschrift für internationale Fragen, Cuaderno 1, p. 3 ss. 
Gornig, Gilbert (1992), «Völkerrechtliche Konsequenzen einer Revolution", en: The European Law Students 'Association (Hrsg.), Osteuropa im Umbruch, p. 5 y ss. GüNTHER, Konrad (1980), «Das Anerkennungsverbot der Homelands», en: German Yearbook of International Law (GYIL), T. 23, p. 323 y ss.

HARDING, Leonhard (1976), Unabhängigkeit der Transkei.

Herrero y Rubio Alejandro (1968), Derecho internacional Público, Valladolid, Gráficas Andrés Martín, Tomo I, p. 234.

Jellinek, Georg (1928), Allgemeine Staatslehre, Berlin, 3. Edición, p. 394 ss.

Jiménez, Eduardo (1995), Derecho internacional Público, Fundación Cultura Universitaria, Tomo II, pág. 22 y 23.

Juste, José y Castillo, Mireya (2002), Derecho internacional Público, Valencia, Editorial Punto y Coma, pp. 204, 205.

Kelsen, Hans (1965), Principios del Derecho internacional Público, Buenos Aires, Editorial El Ateneo, pp. 230, 240, 254.

Kelsen, Hans (1952), Principles of International Law, p. 262

KeLSEN, Hans (1944), «The International Legal Status of Germany to be Established Immediately upon Termination of the War», en: AJIL, T. 38, p. 689 y ss.

Kimminich, Otto (1970), "Deutschland als Rechtsbegriff und die Anerkennung der DDR", in: Deutsches Verwaltungsblatt (DVBl.), pp. 437, 438, 439 y ss.

Kimminich, Otto (1970), Die Souveränität der Bundesrepublik Deutschland, p. 37.

KLEIN, Eckart (1979), «Die Nichtanerkennungspolitik der Vereinten Nationen gegenüber den in die Unabhängigkeit entlassenen südafrikanischen homelands», en: ZaöRV, T. 39, p. 469 y ss.

KunZ, Josef (1955), Identity of States under International Law, en: AJIL, T. 49, p. 68 ss. (69 Anm. 5).

Llanos, Hugo (2006), Teoría y Práctica del Derecho internacional Público, Santiago, Editorial Jurídica de Chile, T-II, Vol. I, p. 57 y ss.

Marek, Krystina (1954), Identity and Continuity of States in Public International
Law, p. 5 y ss., 8, 9, 15, 23, 127 y ss., 186, 189, 366, 412, 414.

Martens, G. Fr. de/Triepel, Heinrich (Hrsg.) (1924), Nouveau Recueil Général de Traités et Autres Actes Relatifs aux Rapports de Droit International (NRG), 3ième serie, T. 13, p. 342 y ss.

Menzel, Eberhard (1962), "Staatensukzession», en: Strupp, Karl/Schlochauer, Han-Jürgen, Wörterbuch des Völkerrechts, T. 3, p. 306 y ss.

Mullerson, Rein (1993), «The Continuity and Succession of States, by Reference to the former USSR and Yugoslavia", en: International and Comparative Law Quarterly (ICLQ), t. 42, p. 473 y ss., 482.

Oeter, Stefan (1986), Die Entwicklung der Westsahara, en: ZaöRV, T. 46, p. 48 ss.

Ortega, Juan (1999), "Aspectos Teóricos y Prácticos de la Continuidad en la Identidad del Estado", en: Anuario de Derecho internacional, $X V$, Editorial del Departamento de Derecho internacional Público, Facultad de Derecho Universidad de Navarra, p., 284 y ss., 303, 308 y 310.

Podestá, Luis (1960), Derecho internacional Público, Buenos Aires, Editorial Tipográfica Editora Argentina, p. 75.

Sánchez de Bustamante y Sirven, Antonio (1945), Manual de Derecho internacional Público, La Habana, Talleres Tipográficos «La Mercantil», p. 29.

SCHweIsfurth, Theodor (1996), «Das Recht der Staatensukzession", en: Berichte der deutschen Gesellschaft für Völkerrecht (BDGVR), T. 35, p. 165.

SILAGI, Michael (1996), Staatuntergang und Staatennachfolge mit besonderer Berücksichtigung des Endes der DDR, pp. $30 \mathrm{y}$ ss. y 36 y ss.

STRUPP, Karl (1911), Urkunden zur Geschichte des Völkerrechts, Ediciones Parthes, Tomo 1, p. 187 y ss

Strupp, Karl (1916), Ausgewählte diplomatische Aktenstücke zur orientalischen Frage, p. 278 ss.

Teyssen, Georg (1987), Deutschlandtheorien auf der Grundlage der Ostvertragspolitik, p. 35 y ss., 74, 80, 88, 106 
UlloA, Alberto (1957), Derecho internacional Público, Madrid, Editorial Iberoamericanas P.A., T. I, pp. 157, 187.

Verdross, Alfred (1964), Völkerrecht, P. 250 y ss.

Verdross, Alfred/Simma, Bruno (1984), Universelles Völkerrecht, S. 224 \$380, P. $231 \rrbracket 391$.
Wilke, Kay-Michael (1976), Bundesrepublik Deutschland und Deutsche Demokratische Republik, p. 26.

Zimmermann, Andreas, Staatennachfolge in völkerrechtlichen Verträgen, 2000, p. 39, 71,77 y ss. 